\title{
Economic Impacts of Coronavirus Disease (COVID-19) in Developing Countries
}

\author{
Tahmina Tasnim Rodela, ${ }^{1}$ Samia Tasnim, ${ }^{2}$ Hoimonty Mazumber, ${ }^{3}$ Farah Faizah, ${ }^{4}$ \\ Abida Sultana, ${ }^{5}$ Md Mahbub Hossain*2
}

\begin{abstract}
The coronavirus disease (COVID-19) has critically impacted global health systems and economies, especially in developing countries. Those countries have been struggling to address the preexisting burden of diseases with limited resources, which will become even more challenging during COVID-19. The economic implications related to COVID-19 in those countries include a high cost of care, market failures in pluralistic health systems, high out-ofpocket expenses, the added burden of noncommunicable diseases, missed economic opportunities, and socioeconomic consequences like unemployment and poverty. It is essential to assess the prevalent gaps, mobilize resources, strengthen health systems financing and leadership, enhance research capacities informing evidence-based policymaking, and foster effective partnerships for addressing health and economic disparities due to COVID-19.
\end{abstract}

Keywords: Coronavirus; COVID-19; Communicable Diseases; Developing Countries; Health Economics

\footnotetext{
${ }^{1}$ Mawlana Bhashani Science and Technology University, Tangail 1902, Bangladesh.

${ }^{2}$ School of Public Health, Texas A\&M University, College Station, TX 77843, USA.

${ }^{3}$ Ipas Bangladesh, Dhaka, Bangladesh.

${ }^{4}$ United Nations Population Fund (UNFPA), Cox's Bazar, Bangladesh.

${ }^{5}$ Gazi Medical College, Khulna 09000, Bangladesh.

*Correspondence at: mhossain@tamu.edu
} 


\section{Introduction}

The coronavirus disease 2019 (COVID-19) is one of the major global health events in the twenty-first century, which has affected almost every nation globally [1]. Since December 2019 , this outbreak caused by a novel coronavirus was found to be structurally related to the viruses that caused severe acute respiratory syndrome (SARS) and the Middle East respiratory syndrome (MERS) [1]. During 2002-03, a total of 8,098 cases of SARS were identified, of these 774 died [2]. The later outbreak by MERS infected 2,494 individuals, among which 858 died since 2012 [3]. However, COVID-19 has clearly exceeded the earlier outbreaks of coronaviruses. As of April 2, 2020, more than a million people from 181 countries are identified as COVID-19 cases, and more than 52,900 deaths are reported due to the disease [4].

With a growing incidence and case fatality attributable to COVID-19, health systems around the world are experiencing critical challenges in terms of preventing disease transmission, diagnosing new cases, providing care, and ensuring recovery [5]. These challenges have heavily impacted many nations with high income and well-structured health infrastructure, which informs how critically it may impact developing countries, which have fragmented health systems with poor population health outcomes [6]. The growing burden of COVID-19 necessitates an understanding of economic implications in the contexts of developing countries to inform effective policymaking and practice during this pandemic.

\section{Economic challenges for the health systems in the developing countries}

Historically, developing countries have suboptimal diagnostic capacities [7], which may have resulted in a low number of COVID-19 cases during the earlier stages of this global outbreak. However, a delayed diagnosis of COVID-19 may lead to hospitalization with a need for critical care support [8]. Such tertiary-level services would cost higher than preventing the disease at earlier stages. It is noteworthy that most healthcare organizations 
in developing countries lack critical care services, which implies that the increased demand for intensive care units or ventilators to stabilize COVID-19 patients may remain unmet.

In developing countries with a lack of universal health coverage, where the market plays a dominant role, the cost of care would also depend on the elasticity of health services and commodities in those contexts [9]. Such economic failures may happen for diverse health services during managing COVID-19 in institutional settings. Moreover, continued shifting of health workforce and resources will create critical distributive issues as patients with other health problems may not receive their designated services during this pandemic. Therefore, health systems in LMICs that are often under-resourced and over-burdened are likely to incur a high cost of care and associated economic failures while addressing COVID-19.

Another major economic challenge during COVID-19 would be a high out-of-pocket (OOP) expenditure in developing countries. Most of those nations healthcare organizations operate within pluralistic health systems incurring OOP for health services [10]. This economic burden is likely to increase during COVID-19 unless state-sponsored diagnostic and therapeutic financing is made available. An increased OOP is associated with subsequent poverty, unemployment, and other socioeconomic consequences, which may affect individuals and populations in the post-COVID-19 era.

Furthermore, many developing countries already have a high burden of comorbid noncommunicable diseases (NCDs) [11], which may increase the hospitalization and mortality across populations while cooccurring with COVID-19. From an economic perspective, such adverse health outcomes will affect the economic returns on existing and newly adopted strategies of health systems financing. In addition, many people with NCDs may experience restricted mobility due to lockdown or lack of transportation, which will affect their access to health services during COVID-19 [12].

The economic consequences of such missed health opportunities will affect developing countries, whereas people living in quarantine or lockdown will have an added risk of 
developing NCDs, which may have prolonged economic implications for respective health systems. Other economic challenges associated with COVID-19 in developing countries may include but not limit into lost wages and insurance benefits of hospitalized individuals, suboptimal use of health services which could have been generated institutional and societal benefits otherwise, and disability-adjusted life years (DALYs) attributable to COVID-19 in those countries [13].

\section{Recommendations for health policymaking and practice}

These implications should be acknowledged across developing countries to address the ongoing and forthcoming economic challenges. As the determinants of health economics would be different for each context, the developing countries should devise rapid situational assessment to understand potential economic issues associated with COVID19. Since most of those countries have a poor allocation of resources for health, it is essential to evaluate the available resources and mobilize the same ensure ensuring costefficiency. Perhaps, balancing between preventive measures and establishing low-cost tertiary management may alleviate the burden of COVID-19 with a minimal economic burden.

Further, it is necessary to strengthen the primary care and referral services so that population health can be served without disrupting existing models of delivering health services. In addition, special attention should be given to elderly adults and other vulnerable groups addressing the specific health needs of those populations [12]. In addition, telemedicine services can be used to ensure appropriate health communication on COVID-19 [14]. However, such approaches may need advanced infrastructure, which may not be readily available in developing countries. Therefore, it would be essential to use the existing resources and develop innovative strategies that can provide cost-effective health services without affecting the ever-shrinking economy during COVID-19. 
Economic challenges often lead to socioeconomic disparities, which should be analyzed from health and social perspective. Developing countries may adopt policies and programs to minimize health disparities and their consequences, which would necessitate strong leadership efforts at institutional and national levels. It would be difficult to address structural barriers without such efforts with a long-term vision. Despite the scarcity of resources, many developing countries have shown promising success in addressing population health problems in the past, which highlight the role of public health leadership. Nonetheless, the severity of public health emergencies may need collaborative efforts among different agencies, which may allow them to utilize shared resources and maximize health and socioeconomic benefits following such collaborations. Large scale outbreaks like COVID-19 may impact the psychosocial wellbeing among populations, which would be hard to measure and manage, especially in developing contexts. Therefore, health and economic research should be prioritized in those countries with regional and global collaborations [15]. Furthermore, a lack of context-specific evidence may affect the development and implementation of health and economic policies. This gap informs a need for enhancing research capacities in developing countries for preventing upcoming crises and building resiliency across health systems in those.

\section{Conclusion}

COVID-19 is affecting global populations indiscriminately; however, the burden of disease and economic consequences can be much greater, potentially under-reported, and underestimated in the developing countries who share a major proportion of the global burden of diseases without adequate preparedness in their health systems. This gap between health problems and abilities to address the same is common across those contexts resulting in adverse economic impacts in a vicious way. Such widespread disparities necessitate multilevel policies and context-specific strategic approaches, ensuring optimal care in COVID-19 minimizing economic challenges in the developing countries. 
Conflicts of interest: The authors declare no conflicts of interests.

Funding: No funding was received at any stage of preparing this manuscript. Acknowledgement: None.

\section{References}

1. Yang P, Wang X. COVID-19: a new challenge for human beings. Cell Mol Immunol [Internet]. 2020 Mar 31 [cited 2020 Apr 3];1-3. Available from: http://www.ncbi.nlm.nih.gov/pubmed/32235915

2. Centers for Disease Control and Prevention. SARS Basics Factsheet [Internet]. 2017 [cited 2020 Apr 3]. Available from: https://www.cdc.gov/sars/about/fssars.html

3. World Health Organization (WHO). Middle East respiratory syndrome coronavirus (MERS-CoV) [Internet]. [cited 2020 Mar 2]. Available from:

https://www.who.int/news-room/fact-sheets/detail/middle-east-respiratorysyndrome-coronavirus-(mers-cov)

4. Johns Hopkins University. COVID-19 Map - Johns Hopkins Coronavirus Resource Center [Internet]. [cited 2020 Apr 4]. Available from: https://coronavirus.jhu.edu/map.html

5. Legido-Quigley H, Asgari N, Teo YY, Leung GM, Oshitani H, Fukuda K, et al. Are high-performing health systems resilient against the COVID-19 epidemic? Vol. 395, The Lancet. Lancet Publishing Group; 2020. p. 848-50.

6. Paintsil E. COVID-19 threatens health systems in sub-Saharan Africa: the eye of the crocodile. J Clin Invest [Internet]. 2020 Mar 30 [cited 2020 Apr 4]; Available from: http://www.ncbi.nlm.nih.gov/pubmed/32224550

7. McNerney R. Diagnostics for Developing Countries. Diagnostics [Internet]. 2015 May 19 [cited 2020 Apr 4];5(2):200-9. Available from: http://www.mdpi.com/2075-4418/5/2/200 
8. Li Q, Guan X, Wu P, Wang X, Zhou L, Tong Y, et al. Early Transmission Dynamics in Wuhan, China, of Novel Coronavirus-Infected Pneumonia. N Engl J Med. 2020 Jan 29;

9. Bloom G, Katsuma Y, Rao KD, Makimoto S, Yin JDC, Leung GM. Next steps towards universal health coverage call for global leadership. BMJ. 2019 May $24 ; 365$.

10. Onah MN, Govender V. Out-of-Pocket Payments, Health Care Access and Utilisation in South-Eastern Nigeria: A Gender Perspective. Molyneux S, editor. PLoS One [Internet]. 2014 Apr 11 [cited 2020 Apr 4];9(4):e93887. Available from: https://dx.plos.org/10.1371/journal.pone.0093887

11. Boutayeb A, Boutayeb S. The burden of non communicable diseases in developing countries. Int J Equity Health. 2005 Jan 14;4(1).

12. Mazumder H, Hossain MM, Das A. Geriatric Care during Public Health Emergencies: Lessons Learned from Novel Corona Virus Disease (COVID-19) Pandemic. J Gerontol Soc Work [Internet]. 2020 [cited 2020 Apr 1];1-2. Available from: https://doi.org/10.1080/01634372.2020.1746723

13. Economics in the Time of Covid-19|VOX, CEPR Policy Portal [Internet]. [cited 2020 Apr 4]. Available from: https://voxeu.org/debates/economics-time-covid-19

14. Tasnim S, Mazumder H, Hossain MM. Impact of rumors or misinformation on coronavirus disease (COVID-19) in social media [Internet]. SocArXiv. 2020 [cited 2020 Apr 4]. Available from: https://osf.io/preprints/socarxiv/uf3zn/

15. Hossain MM. Current Status of Global Research on Novel Coronavirus Disease (COVID-19): A Bibliometric Analysis and Knowledge Mapping. SSRN Electron J [Internet]. 2020 Mar 3 [cited 2020 Mar 8]; Available from: https://www.ssrn.com/abstract $=3547824$ 